\title{
A social skills and assertiveness group for 9- to 11-year-old children: implications for training
}

\author{
S. J. Aldridge and H. J. Campbell
}

An experience by two senior registrars of a social skills group for five 9 to 11-yecr-old children with peer relationship dificulties of school is reported.

Although without experience of leading this type of group, with supervision we were able to usefully draw on our experience in other areas such as family therapy, individual therapy and cognitive behavioural therapy in order to adapt and augment highly structured approaches to social skills training (McGinnis 1984) to successfully plan and execute a social skills group sensitive to the individual needs of our clients.

The group commenced with five children referred with school-based peer difficulties including initiating fights, being the butt of name-calling and difficulties maintaining friendships.

\section{Planning the group sessions}

We started from the premise that where children lack successful strategies in peer relationships one of the following applies (McGinnis, 1984):

(a) an appropriate skill has not been learnt

(b) an adequately learnt skill is insufficiently rewarded

(c) powerful emotions inhibit use of an appropriate skill.

Six weekly 75 minute sessions were allocated. Parents remained on site throughout. Even without a facilitator the parents benefited from knowing their problems were shared, supporting Yalom's (1985) observation of 'universality' as an important therapeutic group process.
Each session had an introduction and a selfesteem building component, followed by work on a relevant task, refreshments and a concluding wind-down phase.

Sessions 1 and 2 focused on forming the group, determining agreed rules, what the children wanted to see change in themselves and their expectations of the group in this regard. To these ends the content of the sessions included introductions, games establishing trust and activities enabling safe disclosure of their difficulties.

Sessions 3 and 4 targeted agreed problem areas encouraging the children to experiment with new strategies. Stages of acquiring new skills were use of modelling initially by leaders; practice of new skill in role play with coaching; positive reinforcement and feedback; and generalisation through homework tasks (McGinnis, 1984).

Sessions 5 and 6 focused on friendship building strategles.

Each session was pre-planned but we were flexible in making it easy for the children to generate ideas about their difficulties.

Some shaping of the children's ideas was required; e.g. one child stated his aim was to lose his temper 'not at all'; this was revised to 'not as often'. The strategy of changing by modest steps and of acknowledging difficulty in achieving even these was employed, an approach commonly used in family and behavioural therapy (Fisch et al, 1982).

We considered that the main adverse effects of group therapy were the risk of colluding with the idea of the problems residing entirely in the child, and that the group would serve to raise expectations of change in the child which might falter at the end of the group session unless the family were able to adapt to such change. These were addressed by offering family therapy in addition to group therapy. 
Table 1. Strategies for name calling: brainstorm

\section{Behovioural tactics}

Tell teacher about it.

Tell name-caller to 'shut-up'.

Get away from the scene.

Retaliate/'smack them'.

Go to talk to someone else/friend.

Count to ten.

Give a physical warning, e.g. show a fist.

Give a verbal warning, e.g. indicate will tell teacher.

Do something else with anger, e.g. punch a punchbag/ stressball.

\section{Cognitive strategies}

Think of good things about yourself, e.g. I've got a great bike.

Think of the name-caller vulnerable, e.g. trousers down on tollet.

Agree with name-called verbally and think 'so whatl'. Imagine energy force field or armour to deflect names. Tell person how you feel, e.g. 'That upsets mel'.

Think of the name-caller as the one with the problem.

Consider the scenario as a game where the namecaller is trying to produce a reaction: as such he/she wins if you help him by retaliating or rising to the bait. In this context doing something different will throw the name-caller off stride so for example 'walking away' can be construed as winning and may take more 'strength' than fighting.

and by excluding children where assessment revealed undersupportive or chaotic home settings.

\section{Establishing a group focus: name-calling and temper control}

By the third session the children agreed to tackle how to control their anger when subjected to name-calling. The group brainstormed possible tactics (Table 1), with the children suggesting several behavioural strategies and the leaders adding a number of cognitive gambits.

Role plays were enacted with the therapists initially modelling coping strategies selected by the group. The therapists then enacted name-calling while each child in turn experimented with an alternative strategy to that they would habitually have used. We deliberately avoided assigning bullying roles to the children.

Each child undertook a homework task trying out the new strategy in a real situation and shared a report on their efforts. Two children chose family based problems with older relatives who were calling them names. We predicted extra difficulties for these children because of the unequal power balance. Such a prediction is realistic and therefore increases the child's sense of being understood, while simultaneously offering a paradoxical element as used at times in family therapy (Cade, 1979). Both these children also used the strategies more successfully at school in peer situations.

One child with depressive features presented her homework as a failure. Closer inspection revealed she had used strategies to control her temper successfully in difficult circumstances. This positive re-evaluation of her homework was accepted both by the child and the group thus redressing her thinking error with a consequent effect upon self-esteem and mood as in cognitive therapy (Beck et al, 1979).

\section{Friendship-building skills}

The final two sessions concentrated on the group's wish to 'get on better with my friends', acknowledging that friendships present opportunities for acquiring a wider repertoire of social skills. Skills practised included asking and responding to questions, expressing interest, and sharing feelings.

Interestingly when brainstorming ideas about friendships the children were, as a group, less able than when generating ideas about temper control when called names. Possibly their energies were occupied with this and hence as a group though not individually they had a range of ideas on this subject; consequently little energy was directed towards developing friendship skills.

\section{Conclusions}

Four children completing the group used new strategies at home and at school with beneficial effect. For example, three of these subjected to name-calling at school reported this had ceased altogether. The fifth child defaulted from both group and family therapy after the second session.

The group sessions were considered too short: 90 minutes would have been more comfortable with two extra sessions exploring friendship skills further.

The ratio of all therapist hours to all patient hours was four to one, approximately evenly spread between the four areas of planning; 
preparing and clearing the rooms; the group itself; and debriefing and supervision. This time investment may not be immediately apparent to inexperienced therapists as seeing several children simultaneously suggests a time-efficient process.

In leading this group our varied training and experience across psychotherapeutic modalities paid dividends: skills learnt in other settings were readily transferred into an area where we were inexperienced. In the light of the Calman Report (Department of Health, 1993) recommendations for restructuring of training of junior doctors in specialities, we feel it is particularly important that child psychiatrists continue to maintain a broadly based training which will facilitate them, both now and in the future, to adopt and be able to supervise a wide variety of therapies which disturbed children may need.

\section{Acknowledgements}

We are indebted to DrL. Hewson, Dr M. Ellis and Ms. A Sabey, Child and Family Unit, Bradford.

\section{References}

BECK, A. T., RUSH, A. J.. SHAw, B. F., et al (1979) Cognittue Therapy of Depression. New York: Guildford.

CADE, B. (1979) The use of pessimism in therapy. Journal of Family Therapy, 1, 23-31.

DEPARTMENT OF HEALTH (1993) Hospital Doctors: Training for the Future. The Report of the Working Group on Specialist Medical Training. (Calman Report). London: HMSO.

Fisch, R., WEAKLAND, J. \& SEGAl, L. (1982) Tactics of Change. San Francisco: Jossey-Bass.

McGinNIS, E. (1984) Skill-streaming the Elementary School Child. Minois: Research Press.

YALOM, I. D. (1985) The Theory and Practice of Group Psychotherapy. New York: Basic Books.

*Correspondence S. J. Aldridge, Consultant, Child and Family Unit, St James University Hospital, Leeds LS9 7TF (formerly Senior Registrar Child and Adolescent Psychiatry, Bradford); and H. J. Campbell, Consultant, Child and Family Consultation Service, County Clinic, James' Green, Kilkenny, Eire (formerly Senior Registrar Child and Adolescent Psychiatry, Bradford 